\title{
ARTICLE
}

\section{Iron isotopic fractionation between silicate mantle and metallic core at high pressure}

\author{
Jin Liu ${ }^{1, \dagger}$, Nicolas Dauphas ${ }^{2}$, Mathieu Roskosz ${ }^{3}$, Michael Y. Hu ${ }^{4}$, Hong Yang ${ }^{5}$, Wenli Bi ${ }^{4,6}$, Jiyong Zhao ${ }^{4}$,
} Esen E. Alp ${ }^{4}$, Justin Y. Hü ${ }^{2}$ \& Jung-Fu Lin ${ }^{1,5}$

The $+0.1 \%$ elevated ${ }^{56} \mathrm{Fe} /{ }^{54} \mathrm{Fe}$ ratio of terrestrial basalts relative to chondrites was proposed to be a fingerprint of core-mantle segregation. However, the extent of iron isotopic fractionation between molten metal and silicate under high pressure-temperature conditions is poorly known. Here we show that iron forms chemical bonds of similar strengths in basaltic glasses and iron-rich alloys, even at high pressure. From the measured mean force constants of iron bonds, we calculate an equilibrium iron isotope fractionation between silicate and iron under core formation conditions in Earth of $\sim 0-0.02 \%$, which is small relative to the $+0.1 \%$ shift of terrestrial basalts. This result is unaffected by small amounts of nickel and candidate core-forming light elements, as the isotopic shifts associated with such alloying are small. This study suggests that the variability in iron isotopic composition in planetary objects cannot be due to core formation.

\footnotetext{
${ }^{1}$ Department of Geological Sciences, Jackson School of Geosciences, University of Texas at Austin, Austin, Texas 78712, USA. ${ }^{2}$ Origins Laboratory, Department of the Geophysical Sciences and Enrico Fermi Institute, The University of Chicago, 5734 South Ellis Avenue, Chicago, Illinois 60637, USA. 3 IMPMC-UMR CNRS 7590, Sorbonne Universités, UPMC, IRD, MNHN, Muséum National d'Histoire Naturelle, 61 rue Buffon, 75005 Paris, France.

${ }^{4}$ Advanced Photon Source, Argonne National Laboratory, Argonne, Illinois 60439, USA. ${ }^{5}$ Center for High Pressure Science and Technology Advanced Research (HPSTAR), Pudong, Shanghai 201203, China. ${ }^{6}$ Department of Geology, University of Illinois at Urbana-Champaign, Urbana, Illinois 61801, USA. $\dagger$ Present address: Department of Geological Sciences, Stanford University, Stanford, California 94305, USA. Correspondence and requests for materials should be addressed to J.L. (email: jinliu@utexas.edu) or to N.D. (email: dauphas@uchicago.edu) or to J.-F.L. (email: afu@jsg.utexas.edu).
} 
ron, as one of the most abundant non-volatile elements in the Solar System, plays a major role in every stage of planetary formation and differentiation. Much information can be gained on these processes by studying iron isotopic variations ${ }^{1-8}$. A striking feature of the Earth is the manner in which it is stratified into a core dominated by metallic $\mathrm{Fe}^{0}$, a mantle that is rich in ferrous $\mathrm{Fe}^{2+}$, and surface oxidative environments where iron is found mostly as ferric $\mathrm{Fe}^{3+}$ (ref. 9). Understanding how this stratification was established has important bearing on several questions in Earth and planetary sciences, such as the nature of the material accreted by the Earth as a function of time $\mathrm{i}^{10,11}$ and the cause for the Great Oxygenation Event ${ }^{12}$. The abundance and redox state of iron in Earth's mantle reflects the redox conditions that prevailed during and after core formation ${ }^{13,14}$. Iron isotopes add a new dimension to this system but progress in interpreting $\mathrm{Fe}$ isotope variations has been hampered by the paucity of equilibrium isotopic fractionation factors under the $P-T$ conditions relevant to core formation.

Mid-ocean ridge basalts (MORBs), which constitute the bulk of Earth's oceanic crust, are enriched in the heavy isotopes of iron by $\sim+0.1 \%$ relative to chondrites (ref. $6 ; \delta^{56} \mathrm{Fe}$ is the deviation in permil of the ${ }^{56} \mathrm{Fe} /{ }^{54} \mathrm{Fe}$ ratio relative to the IRMM-014 standard, whose composition is indistinguishable from chondrites). In contrast, basalts from Mars and Vesta have the same $\delta^{56} \mathrm{Fe}$ value as chondrites within uncertainty $2,4,5,15,16$. The non-chondritic Fe isotope composition of terrestrial basalts has been interpreted as resulting from iron vaporization into space during the Moonforming giant impact ${ }^{2}$, high-temperature and high-pressure equilibrium fractionation between metal and silicate during core formation ${ }^{7,8}$, or iron isotopic fractionation during partial mantle melting to produce Earth's crust ${ }^{17-20}$. Supporting the last explanation is the observation that mantle peridotites have an iron isotopic composition that is close to that of chondrites ${ }^{17,19}$. However, mantle peridotites are imperfect proxies of the mantle composition, as they have been affected by partial melting and metasomatism $^{17,21,22}$, which can fractionate Fe isotopes.

To test the core-mantle segregation mechanism and set constraints on the conditions of core formation, it is critical to know how iron isotopes are partitioned at equilibrium between metal and silicate under conditions relevant to core formation. Previous studies have investigated metal-silicate $\mathrm{Fe}$ isotopic fractionation at high temperature and relatively low pressure, reaching the conclusion that the fractionation would be negligible ${ }^{23,24}$. However, pressure is an important intensive parameter that affects the strength of iron bonds and the structure of silicates, so iron isotopic fractionation between silicate and metal might differ at high pressure ${ }^{7,25}$.

Polyakov $^{7}$ used previously published results from nuclear resonant inelastic X-ray scattering spectroscopy (NRIXS) to conclude that the equilibrium iron isotopic fractionation between metallic iron and silicate post-perovskite under Earth's coremantle boundary conditions may be sufficiently large to impart a measurable isotopic shift to the mantle. The NRIXS data used to support this claim are of insufficient precision at the low- and high-energy ends of the spectrum to derive reliable force constant values $^{20}$. Furthermore, silicate post-perovskite would not be stable in the hot lowermost mantle of early Earth ${ }^{26}$ and its role in setting the present Fe isotopic signature of MORBs is uncertain.

Shahar et al. ${ }^{25}$ investigated iron isotope fractionation between bridgmanite and iron alloys $\left(\mathrm{FeO}, \mathrm{FeH}_{x}\right.$ and $\left.\mathrm{Fe}_{3} \mathrm{C}\right)$ at pressures relevant to core formation in a typical magma ocean setting, up to $\sim 60 \mathrm{GPa}$, by using NRIXS spectroscopy complemented by theoretical calculations. They found that the effect of pressure on iron isotopic composition is different among iron-light element alloys investigated. Notably, the $\delta^{56} \mathrm{Fe}$ value of the current terrestrial mantle would be fractionated by $\sim+0.02 \%$ relative to the bulk Earth composition for a pure iron core and this fractionation would increase to $\sim+0.04 \%$ o for an $\mathrm{FeH}_{x}$ or $\mathrm{Fe}_{3} \mathrm{C}$ core. Hydrogen and carbon are, however, unlikely major light element candidates in Earth's core ${ }^{27,28}$. Oxygen is more probable but Shahar et al. ${ }^{25}$ showed that it would induce a limited shift in the Fe isotopic composition of the mantle $(\sim+0.02 \%)$.

The studies done so far have focused on crystalline phases as analogues to the magma ocean silicate melt ${ }^{7,25}$. Furthermore, the effects of $\mathrm{Si}, \mathrm{S}$ (two of the major light element candidates in the Earth's core) and $\mathrm{Ni}$ alloying with $\mathrm{Fe}$ on iron isotopic fractionation remain uncertain. Therefore, it is crucial to examine iron isotopic fractionation between silicate glasses of basaltic composition and iron-rich alloys of $\mathrm{Fe}-\mathrm{Ni}$-Si, $\mathrm{Fe}-\mathrm{Si}$ and $\mathrm{Fe}-\mathrm{S}$, to evaluate whether core formation could have fractionated the iron isotopic composition of Earth's mantle.

Here we report the experimental determination of the mean force constant $\langle F\rangle$ of iron bonds in synthetic samples of basaltic glass, metallic iron and iron-rich alloys of $\mathrm{Fe}-\mathrm{Ni}-\mathrm{Si}, \mathrm{Fe}-\mathrm{Si}$ and Fe-S up to $206 \mathrm{GPa}$. We find that all $\langle F\rangle$ values increase with pressure, and that the $\langle F\rangle$ values of silicate glass are comparable to those of metal. Our results suggest that the interplanetary variability in iron isotopic composition cannot be due to core formation.

\section{Results}

Experimental approach. We studied the high-pressure equilibrium Fe isotopic fractionation between basaltic glass and Fe-rich $\mathrm{Fe}-\mathrm{Ni}-\mathrm{Si}, \mathrm{Fe}-\mathrm{Si}$ and $\mathrm{Fe}-\mathrm{S}$ solid alloys (taken as proxies for molten silicates $^{29-31}$ and alloys, respectively) using NRIXS spectroscopy with samples loaded in diamond anvil cells (DACs) ${ }^{7,32}$. NRIXS gives the mean force constant of iron bonds $\langle F\rangle$, from which reduced partition function ratios or $\beta$-factors can be deduced through $^{32}$,

$$
1,000 \ln \beta=2,904 \frac{\langle F\rangle}{T^{2}} .
$$

The $\beta$-factors give the extent to which ${ }^{56} \mathrm{Fe} /{ }^{54} \mathrm{Fe}$ ratios are fractionated between coexisting phases at equilibrium,

$$
\left(\delta^{56} \mathrm{Fe}_{B}-\delta^{56} \mathrm{Fe}_{A}\right)_{\mathrm{eq}}=1,000\left(\ln \beta_{B}-\ln \beta_{A}\right) .
$$

The starting samples were a fully reduced ${ }^{57} \mathrm{Fe}$-enriched basaltic glass containing only $\mathrm{Fe}^{2+}$ (ref. 20), polycrystalline $\mathrm{Fe}$ and $\mathrm{Fe}_{86.8} \mathrm{Ni}_{8.6} \mathrm{Si}_{4.6}, \mathrm{Fe}_{85} \mathrm{Si}_{15}$ and $\mathrm{Fe}_{3} \mathrm{~S}$ alloys ${ }^{33-35}$. Conventional Mössbauer spectroscopic data, electron microprobe analyses and NRIXS data collected on the basaltic glass at ambient conditions were reported elsewhere ${ }^{20}$. Metal iron and the iron-based alloys were examined by X-ray diffraction and most were in a bodycentred cubic structure at ambient conditions, except for $\mathrm{Fe}_{3} \mathrm{~S}$, which was in the tetragonal structure. The reported $\langle F\rangle$ values for $\mathrm{Fe}_{92} \mathrm{Ni}_{8}, \mathrm{Fe}_{85} \mathrm{Si}_{15}$ and $\mathrm{Fe}_{3} \mathrm{~S}$ are based on newly acquired NRIXS data combined with previous data from Lin et al. ${ }^{34,35}$, who did not report the $\langle F\rangle$ values for $\mathrm{Fe}_{92} \mathrm{Ni}_{8}$ and $\mathrm{Fe}_{85} \mathrm{Si}_{15}$. For previously acquired data, the uncertainties on the $\langle F\rangle$ values are large due to the relatively narrow energy scans acquired, as those studies focused on the determination of the Debye sound velocity for seismological applications.

Although the phases relevant to core formation conditions are molten, direct measurements of vibrational properties on silicate and metallic liquids under ultrahigh pressure conditions are currently beyond experimental capabilities. Still, the behaviours of silicate melts under high $P-T$ conditions can be understood by examining silicate glasses, because both exhibit similar microscopic and macroscopic properties ${ }^{29,30}$. For instance, the inelastic vibrational properties of silicate glasses are close to their molten counterparts $^{36}$ and changes in the $\mathrm{Si}-\mathrm{O}$ coordination number of 
molten basalt are in excellent agreement with those observed in silica glass at pressures up to $60 \mathrm{GPa}$ (ref. 37). Similarly, for lack of better alternatives, crystalline iron is often used as proxy for molten iron in deep Earth studies. Molten iron is described as a simple close-packed liquid ${ }^{38}$ and exhibits comparable density and compressibility relative to its solid phase under core conditions ${ }^{39}$. As a first pass on this question and following Polyakov ${ }^{7}$ and Shahar et al..$^{25}$, we take the $\langle F\rangle$ values of iron bonds in solid $\mathrm{Fe}$ and Fe-rich alloys to be proxies of those in their liquid counterparts. We use new data for the most relevant candidate light elements $\mathrm{Si}$ and $\mathrm{S}$, and for the main alloying element $\mathrm{Ni}$, together with literature data for $\mathrm{FeH}_{x}, \mathrm{Fe}_{3} \mathrm{C}$ and $\mathrm{FeO}$ alloys from Shahar et al. ${ }^{25}$, to fully evaluate how alloying and light elements affect iron $\beta$-factors of pure iron under high- $P, T$ conditions.

High- $T$ harmonic extrapolation. Measurements of the force constant of iron bonds at room temperature were used to calculate the iron $\beta$-factors using equation (1), which assumes harmonic behaviour $7,20,25,32,40$ (see Methods). At the high temperatures relevant to core formation on Earth, the iron $\beta$-factors could be affected by anharmonic effects, but such effects may be largely suppressed by the associated high pressures ${ }^{7}$. Furthermore, theoretical caculations ${ }^{25,41-43}$ support the validity of the harmonic approximation for calculation of $\beta$-factors at high temperatures. For instance, the correction on the iron $\beta$-factors between $0 \mathrm{~K}$ and mantle temperatures is thought to be negligible ${ }^{25}$. NRIXS predictions have previously been shown to be in agreement with independent determination of equilibrium fractionation factors based on mass spectrometry analyses of coexisting phases thought to have achieved equilibrium. This is the case for magnetite and olivine at 873-1,073 K (refs 40,44). This is also the case for basaltic glass and iron, for which NRIXS data $^{20}$ agree with equilibration experiments performed in the molten silicate-metal system at $1,573 \mathrm{~K}$ and $1 \mathrm{GPa}$ (ref. 24), and $2,273 \mathrm{~K}$ and $7.7 \mathrm{GPa}$ (ref. 23). These agreements support the use of solid phases (silicate glass and crystalline alloys) as proxies for melts.

Iron isotopic fractionation between Earth's mantle and core. The $\langle F\rangle$ values of iron bonds of all investigated phases increase considerably with pressure (Fig. 1). The $\langle F\rangle$ values of iron bonds in basaltic glass increase by $\sim 40 \%$ from 26 to $35 \mathrm{GPa}$ (Fig. 1a), likely to be associated with the formation of tricluster oxygen ${ }^{29}$ and structural change ${ }^{37}$ in silicate glasses and melts. In contrast, no obvious discontinuity is observed in the $\langle F\rangle$ values of the alloys, which define linear trends with pressure (Fig. 1b-d). Even for $\mathrm{Fe}_{86.8} \mathrm{Ni}_{8.6} \mathrm{Si}_{4.6}$, no significant offset is measured when the alloy transitions from body-centred cubic to hexagonal closepacked at $\sim 20 \mathrm{GPa}$ (Fig. 1c). The $\langle F\rangle$ values of pure iron reported in the present study are identical within uncertainty to those of iron derived from NRIXS and theoretical calculations by Shahar et al. ${ }^{25}$ In details, however, the $\langle F\rangle$ values calculated from a fit to their data are systematically greater than ours by $\sim 12 \mathrm{~N} \mathrm{~m}^{-1}$, which corresponds to a negligible difference of $\sim 0.003 \%$ in predicted $\beta$-factors at 3,500 K (Fig. 1b).

Linear fits to measured $\langle F\rangle$ values versus $P$ were calculated (Table 1), from which one can calculate the $\beta$-factor of basaltic glass, pure iron and Fe-rich alloy at any $P-T$ conditions (Supplementary Figs 4 and 5). The quantity that we are interested in is the fractionation between metal and silicate under the conditions relevant to core formation conditions $(\sim 40-60 \mathrm{GPa}$ and 3,000-4,000 K for single-stage equilibration ${ }^{45-47}$ ). The silicate $\beta$-factor is given by the basaltic glass. For metal, the $\beta$-factor may be influenced by the composition of the alloy, which is shown in Figs 2 and 3 at a reference value of $3,500 \mathrm{~K}$ and variable pressures.

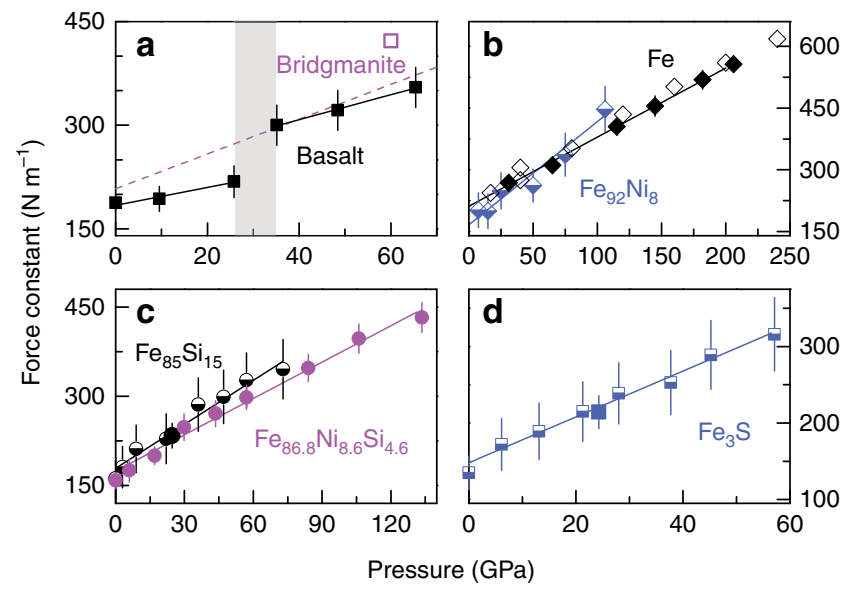

Figure 1 | Force constants of iron bonds in basaltic glass and Fe and iron-rich alloys as a function of pressure. Black and blue solid squares, black solid diamonds, and black and magenta solid circles: basaltic glass (a), $\mathrm{Fe}(\mathbf{b}), \mathrm{Fe}_{85} \mathrm{Si}_{15}$ (c), $\mathrm{Fe}_{86.8} \mathrm{Ni}_{8.6} \mathrm{Si}_{4.6}$ (c) and $\mathrm{Fe}_{3} \mathrm{~S}$ (d), respectively, from this study (Supplementary Table 2); half-filled diamonds, circles and squares: $\langle F\rangle$ values for $\mathrm{Fe}_{92} \mathrm{Ni}_{8}, \mathrm{Fe}_{85} \mathrm{Si}_{15}$ and $\mathrm{Fe}_{3} \mathrm{~S}$ evaluated based on the NRIXS data from Lin et al. ${ }^{34,35}$ using the SciPhon software; open square and diamonds: bridgmanite and Fe reported by Shahar et al. ${ }^{25}$; dashed line: bridgmanite reported by Rustad and $\mathrm{Yin}^{56}$. The error bars are 95\% confidence intervals. Each high-pressure data point was measured at least 20 times and as many as 47 times. Solid lines: linear fits to the data for the basaltic glass, Fe and iron-rich alloys. Note the large shift in $\langle F\rangle$ value of the basaltic glass (a) at $\sim 30 \mathrm{GPa}$, which corresponds to structural changes in the glass 29,37

Except for $\mathrm{FeH}_{x}$, the predicted 1,000 $\ln \beta$-values of the alloys are within $\sim \pm 0.01 \%$ of the pure Fe value.

\section{Discussion}

The temperature of metal-silicate equilibration in the early Earth is uncertain, because it is usually calculated from the pressure of equilibration assuming that Earth's mantle was close to the liquidus temperature of the silicate. The liquidus temperature itself is uncertain and it is possible that the silicate mantle was superheated in the aftermath of giant impacts, so that the temperatures were higher than those given by the liquidus ${ }^{48}$ Previous studies on the partitioning behaviour of moderately siderophile elements constrain the pressure-temperature conditions for high-pressure core formation in the Earth to be $\sim 40-60 \mathrm{GPa}$ and $\sim 3,000-4,000 \mathrm{~K}$, possibly accompanying deep magma oceans extending to $>1,000 \mathrm{~km}$ depth $^{45-47}$. In the Earth, $\sim 87 \%$ of the iron inventory is in the core, meaning that the silicate-metal equilibrium fractionation would be expressed in the mantle. Assuming a chondritic bulk Earth composition, the shift imposed on the mantle $\delta^{56} \mathrm{Fe}$ value by core formation would depend on the alloy composition (Fig. 4).

The theoretically derived iron $\beta$-factor of bridgmanite obtained by Shahar et al. ${ }^{25}$ are larger by $\sim 20 \%$ than the $\beta$-factor measured on the basaltic glass at $\sim 40-60 \mathrm{GPa}$. As a result, the fractionation values that they calculated were systematically heavier than ours by $\sim 0.01-0.02 \%$ at approximately $40-60 \mathrm{GPa}$ and $3,500 \mathrm{~K}$. For instance, for the $\mathrm{Fe}-\mathrm{C}$ core model, the calculated $\delta^{56} \mathrm{Fe}_{\text {Mantle value }}$ is $\sim+0.01-0.03 \%$ using basaltic glass data from the present study, whereas Shahar et al. ${ }^{25}$ calculated a $\delta^{56} \mathrm{Fe}_{\text {Mantle value of }}$ $\sim+0.03-0.05 \%$ based on first-principles calculations of iron $\beta$-factor of bridgmanite. Although we agree with Shahar et al. ${ }^{25}$ that $\mathrm{FeHx}$ and $\mathrm{Fe}_{3} \mathrm{C}$ would lead to the largest shifts in $\delta^{56} \mathrm{Fe}$ values, we find that the shift would be smaller than what they predicted by $0.01-0.02 \%$. 
Table 1 | Pressure dependence of the force constant $\langle\boldsymbol{F}\rangle$ values of iron bonds in basaltic glass and Fe-rich alloys.

\begin{tabular}{|c|c|c|c|c|}
\hline Sample & Pressure range (GPa) & $a\left(\mathrm{~N} \mathrm{~m}^{-1} \mathrm{GPa}^{-1}\right)$ & $b\left(\mathrm{~N} \mathrm{~m}^{-1}\right)$ & $R^{2}$ \\
\hline \multirow[t]{2}{*}{ Basaltic glass } & $0-26$ & $1.29( \pm 0.24)$ & $184.1( \pm 4.5)$ & 0.929 \\
\hline & $35-65$ & $1.81( \pm 0.09)$ & $235.8( \pm 5.1)$ & 0.994 \\
\hline $\mathrm{Fe}$ & $0-206$ & $1.68( \pm 0.04)$ & $211.7( \pm 4.7)$ & 0.998 \\
\hline $\mathrm{Fe}_{92} \mathrm{Ni}_{8}{ }^{*}$ & $8-106$ & $2.50( \pm 0.26)$ & $167.0( \pm 17.3)$ & 0.950 \\
\hline $\mathrm{Fe}_{85} \mathrm{Si}_{15}{ }^{\star}$ & $0-70$ & $2.46( \pm 0.19)$ & $178.9( \pm 7.8)$ & 0.960 \\
\hline $\mathrm{Fe}_{3} \mathrm{~S}^{\star}$ & $0-57$ & $2.99( \pm 0.21)$ & $148.0( \pm 6.9)$ & 0.966 \\
\hline
\end{tabular}

The linear relationships between the force constant $\langle F\rangle$ and pressure $(P)$ for those samples were expressed as $\langle F\rangle=a \times P+b$, with $\langle F\rangle$ in the unit of $\mathrm{N} / \mathrm{m}$ and $P$ in the unit of $\mathrm{GPa}$.

${ }^{*}$ The $\langle F\rangle$ values of iron bonds in $\mathrm{Fe}_{92} \mathrm{Ni}_{8}, \mathrm{Fe}_{85} \mathrm{Si}_{15}$, and $\mathrm{Fe}_{3} \mathrm{~S}$ were calculated from this study and NRIXS data from Lin et al. ${ }^{34,35}$. The $\left\langle F>\right.$ values for $\mathrm{Fe}_{85} \mathrm{Si}_{15}$ and $\mathrm{Fe}_{3} \mathrm{~S}$ (corresponding to solid symbols in Fig. 1c,d) at $\sim 24 \mathrm{GPa}$ from this study are in agreement with those (corresponding to half-filled symbols in Fig. 1c,d) calculated by using the SciPhon software with previous NRIXS data, demonstrating the reproducibility of NRIXS results.

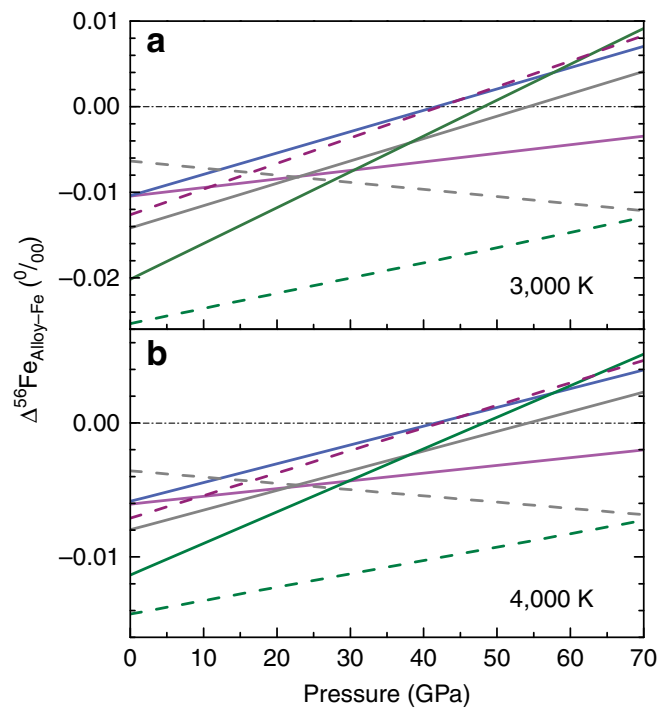

Figure 2 | Comparisons of $\beta$-factors of iron-rich alloys at high pressure and temperature. Difference in the ${ }^{56} \mathrm{Fe} /{ }^{54} \mathrm{Fe} \beta$-factors of iron-rich alloys with respect to pure iron at 3,000 K (a) and 4,000 K (b) as a function of pressure. Magenta, blue, grey and olive solid lines: $\mathrm{Fe}_{86.8} \mathrm{Ni}_{8.6} \mathrm{Si}_{4.6}, \mathrm{Fe}_{85} \mathrm{Si}_{15}$, $\mathrm{Fe}_{92} \mathrm{Ni}_{8}$ and $\mathrm{Fe}_{3} \mathrm{~S}$ alloys, respectively, from this study. Purple, grey and olive dashed lines: $\mathrm{FeO}, \mathrm{Fe}_{3} \mathrm{C}$ and $\mathrm{FeH}_{x}$, respectively, from Shahar et al. ${ }^{25}$ $\Delta^{56} \mathrm{Fe}_{\text {Alloy-Fe }}=\delta^{56} \mathrm{Fe}_{\text {Alloy }}-\delta^{56} \mathrm{Fe}_{\mathrm{Fe}}=1,000 \times\left(\ln \beta_{\text {Alloy }}{ }^{56 / 54} \mathrm{Fe}-\ln \beta_{\mathrm{Fe}}{ }^{56 / 54} \mathrm{Fe}\right)$. Black dash-dotted lines represent no iron isotopic fractionation between Fe-rich alloys and pure iron.

Earth's core is unlikely to contain much $\mathrm{H}$ and $\mathrm{C}^{27,28}$ and the most probable alloying elements, in addition to $\mathrm{Ni}$, are $\mathrm{O}, \mathrm{Si}$ and S. Our results agree with the conclusion by Shahar et al..$^{25}$ that $\mathrm{FeO}$ alloy would induce a negligible shift in the $\delta^{56} \mathrm{Fe}$ value of the mantle (Fig. 4). An important conclusion of the present work is that other alloys of $\mathrm{Fe}-\mathrm{S}, \mathrm{Fe}-\mathrm{Si}$ and $\mathrm{Fe}-\mathrm{Ni}$-Si would also produce minimal isotopic fractionation in the silicate mantle relative to the bulk Earth. The inferred core-mantle Fe isotopic fraction at $\sim 40-60 \mathrm{GPa}$ and $\sim 3,000-4,000 \mathrm{~K}$ for $\mathrm{O}, \mathrm{Si}$ and $\mathrm{S}$ alloys is approximately five to ten times smaller than the observed $\mathrm{Fe}$ isotope composition for MORBs $\left(\delta^{56} \mathrm{Fe}\right.$ of $\sim+0.1 \%$ relative to chondrites $)^{6}$. Our results thus indicate that high-pressure mantlecore equilibration cannot be responsible for the heavy Fe isotopic composition measured in basalts (Fig. 4). Therefore, our results reveal that the $\mathrm{Fe}$ isotopic composition of the mantle is representative of the bulk Earth and provides a baseline with which to compare the composition of extraterrestrial samples.

Our results also have some bearing on the iron isotopic compositions of rocks from Mars (SNC meteorites), Vesta (HED meteorites) and the angrite parent body. The $P-T$ conditions of

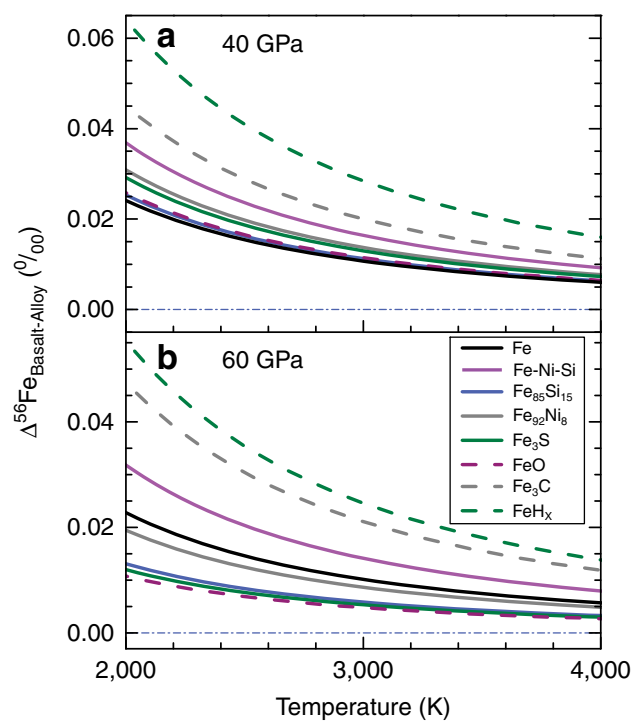

Figure 3 | Equilibrium ${ }^{56} \mathrm{Fe} /{ }^{54} \mathrm{Fe}$ isotope fractionation between basaltic glass and iron-rich alloys at high pressure and temperature. $\mathbf{a}$. Pressure at $40 \mathrm{GPa}$. b. Pressure at $60 \mathrm{GPa}$. Black, magenta, blue, grey and olive solid lines: $\mathrm{Fe}, \mathrm{Fe}_{86.8} \mathrm{Ni}_{8.6} \mathrm{Si}_{4.6}, \mathrm{Fe}_{85} \mathrm{Si}_{15}, \mathrm{Fe}_{92} \mathrm{Ni}_{8}$, and $\mathrm{Fe}_{3} \mathrm{~S}$ alloys, respectively, from this study. Purple, grey and olive dashed lines: $\mathrm{FeO}, \mathrm{Fe}_{3} \mathrm{C}$ and $\mathrm{FeH}_{x}$ respectively, from Shahar et al. ${ }^{25} \Delta^{56} \mathrm{Fe}_{\text {Basalt-Alloy }}=\delta^{56} \mathrm{Fe}_{\text {Basalt }}-\delta^{56} \mathrm{Fe}_{\text {Alloy. }}$. Blue dash-dotted lines represent no iron isotopic fractionation between basaltic glass and Fe-rich alloys.

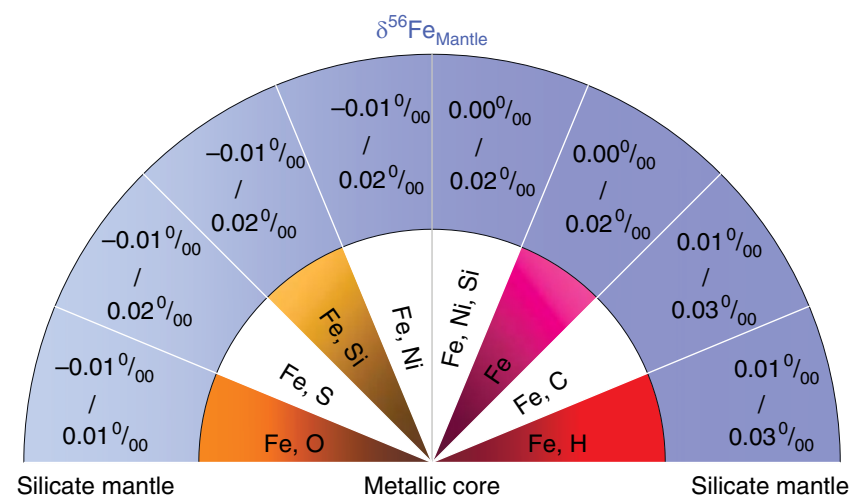

Figure 4 | Predicted shifts in the iron isotopic composition of the silicate mantle due to core formation. Schematics for $\delta^{56} \mathrm{Fe}$ isotope signatures in the bulk silicate Earth (primitive mantle) with regard to varying compositional models of Earth's core. The segregating metal was assumed to equilibrate with the silicate mantle at the base of the magma ocean at $\sim 50 \mathrm{GPa}$ and 3,500 $\mathrm{K}$ based on refs 45-47. 
core formation in those planetary bodies are inferred to be $\sim 6 \mathrm{GPa}-1,900 \mathrm{~K}$ for Mars ${ }^{49}, \sim 0.0001 \mathrm{GPa}-1,873 \mathrm{~K}$ for Vesta ${ }^{49}$ and $<0.5 \mathrm{GPa}-2,173 \mathrm{~K}$ for the angrite parent body ${ }^{50}$. Under these conditions, we calculate that as on Earth, the equilibrium iron isotopic fractionation should be small $(<0.02 \%)$. Even if significant $\mathrm{S}$ is present in cores of these bodies, the results for $\mathrm{Fe}_{3} \mathrm{~S}$ indicate that the fractionation would be minimal. This is consistent with the fact that SNC and HED meteorites have near-chondritic $\mathrm{Fe}$ isotopic compositions ${ }^{2,15}$. It does not explain, however, the heavy $\mathrm{Fe}$ isotopic composition of angrites $(\sim+0.1 \% \text { relative to chondrites })^{51}$. In that case, other interpretations must be sought, which based on $\mathrm{Si}$ isotope systematics may involve isotopic fractionation during condensation in the solar nebula ${ }^{52}$ or impact-induced vaporization ${ }^{53}$. The emerging picture from this study supports the notion that core formation of planetary bodies in the Solar System is unlikely to fractionate significantly stable isotope ratios for elements such as $\mathrm{Si}, \mathrm{Cr}$ and $\mathrm{Fe}$. Other processes such as gas-solid fractionation in the nebula, impact-induced vaporization, or magma generation must be responsible for explaining the isotopic diversity of terrestrial and extraterrestrial rocks.

\section{Methods}

Sample synthesis. As the NRIXS technique is only sensitive to the Mössbauer isotope ${ }^{57} \mathrm{Fe}$, phases enriched in this isotope were synthesized in the laboratory from almost pure ${ }^{57} \mathrm{Fe}$-oxide and metal. The ${ }^{57} \mathrm{Fe}$-enriched tholeiitic basalt glass sample was synthesized from a mixture of $\mathrm{SiO}_{2}, \mathrm{Al}_{2} \mathrm{O}_{3}, \mathrm{CaCO}_{3}, \mathrm{MgO}, \mathrm{Na}_{2} \mathrm{CO}_{3}$, $\mathrm{K}_{2} \mathrm{CO}_{3}, \mathrm{TiO}_{2}$ and $\mathrm{Fe}$-enriched $\mathrm{Fe}_{2} \mathrm{O}_{3}$ in vertical gas mixing furnaces at the University of Lille and at CRPG-Nancy (France). The oxygen fugacity $\left(f \mathrm{O}_{2}\right)$ was controlled using $\mathrm{CO} / \mathrm{CO}_{2}$ gas mixtures. The chemical composition and homogeneity of the glass was examined using electron microprobe and Mössbauer spectroscopy. Its composition is $\mathrm{Na}_{0.036} \mathrm{Ca}_{0.220} \mathrm{Mg}_{0.493} \mathrm{Fe}_{0.115} \mathrm{Al}_{0.307} \mathrm{Ti}_{0.012} \mathrm{~K}_{0.002}$ $\mathrm{Si}_{0.834} \mathrm{O}_{3}$ with $\mathrm{Fe}^{3+} / \mathrm{Fe}_{\text {total }}<0.02$ (see ref. 20 for more details of the synthesis process). The pure Fe powder sample (with an enrichment of $>95 \%{ }^{57} \mathrm{Fe}$ ) was purchased from Cambridge Isotope Laboratories, Inc. The Fe-rich $\mathrm{Fe}_{86.8} \mathrm{Ni}_{8.6} \mathrm{Si}_{4.6}$ alloy was synthesized from a mixture of powder $\mathrm{Fe}, \mathrm{Ni}$ and $\mathrm{Si}$ in an arc furnace in a pure Ar atmosphere at the Max Planck Institute for Solid State Research, Stuttgart, and Bayerisches Geoinstitut, University of Bayreuth ${ }^{33}$. The $>95 \%{ }^{57} \mathrm{Fe}$-enriched $\mathrm{Fe}_{85} \mathrm{Si}_{15}$ alloy was synthesized from a homogeneous mixture of $\mathrm{Fe}$ and $\mathrm{Si}$ by arc melting at the Advanced Photon Source, Argonne National Laboratory, USA ${ }^{34}$. The $\sim 65 \%{ }^{57} \mathrm{Fe}$-enriched $\mathrm{Fe}_{3} \mathrm{~S}$ sample was synthesized from the starting materials of ${ }^{57} \mathrm{Fe}$-enriched iron and troilite (FeS) in a multianvil apparatus at the Geophysical Laboratory, Carnegie Institution of Washington ${ }^{35}$.

High-pressure synchrotron NRIXS experiments. We conducted in situ highpressure NRIXS experiments on basaltic glass, Fe and Fe-rich alloys in DACs up to $206 \mathrm{GPa}$ at sector 3ID-B of the Advanced Photon Source, Argonne National Laboratory (Supplementary Fig. 1). Each ${ }^{57} \mathrm{Fe}$-enriched sample was separately loaded into a sample chamber drilled into a beryllium gasket in a panoramic DAC. The starting samples of approximately $10-15 \mu \mathrm{m}$ in thickness and $30 \mu \mathrm{m}$ in diameter were loaded into panoramic DACs with culet sizes ranging from 50 to $400 \mu \mathrm{m}$ in diameter, with Be gaskets of $3 \mathrm{~mm}$ in diameter and cubic boron nitride gasket inserts. For the basaltic glass, $\mathrm{Fe}$ and $\mathrm{Fe}-\mathrm{Ni}-\mathrm{Si}$ alloy, each NRIXS spectrum was scanned around the nuclear transition energy of ${ }^{57} \mathrm{Fe}$ with a step size of $0.25 \mathrm{meV}$ and a collection time of $5 \mathrm{~s}$ per energy step with an energy resolution of $1 \mathrm{meV}$. For the Fe-S and Fe-Si alloys, the scan step size was increased to $0.5 \mathrm{meV}$ with an energy resolution of $2 \mathrm{meV}$, to increase the count rate for the inelastic peaks. Each NRIXS scan took about 1-1.5 h. Owing to the dilute Fe content in the basalt glass sample and the extended energy acquisition range, 20-47 NRIXS scans (approximately 2-3 days of beamtime) per pressure were collected and combined in order to achieve good statistics. All the NRIXS measurements were made at room temperature $(\sim 300 \mathrm{~K})$. A broad energy range (for example, from -110 to $+140 \mathrm{meV}$ for the basaltic glass) was scanned at high pressures, which is important to capture multiphonon contributions and possible high-energy vibration modes for the reliable determination of $\langle F\rangle$. values ${ }^{20}$ (Supplementary Table 1). Pressure was calibrated using the ruby scale ${ }^{54}$ for the basaltic glass, Fe and Fe alloys below $70 \mathrm{GPa}$. Above $70 \mathrm{GPa}$, the Raman spectra of the diamond anvils were collected for use as a pressure gauge before and after each measurement ${ }^{55}$. The pressure was cross-checked with the previously characterized equation of state of $\mathrm{Fe}$ and $\mathrm{Fe}-\mathrm{Ni}-\mathrm{Si}$ alloy ${ }^{33}$.

SciPhon software and data analysis. We applied a new approach based on moment calculations of NRIXS scattering spectra $S(E)$ using the SciPhon software, as this method allows a better assessment of measurement uncertainties and potential systematic errors than using moments of the phonon density of states $^{32,41}$. In the quasiharmonic lattice model, the third moment $R_{3}$ of a measured NRIXS spectrum $S(E)$ is used to calculate the mean force constant $\langle F\rangle$ of iron bonds in the samples (in $\mathrm{N} / \mathrm{m})^{32,41}$ :

$$
\langle F\rangle=\frac{M}{E_{R} \hbar^{2}} R_{3}=\frac{M}{E_{R} \hbar^{2}} \int_{-\infty}^{+\infty}\left(E-E_{R}\right)^{3} S(E) \mathrm{d} E
$$

where $M$ is the mass of the nuclear resonant isotope $\left({ }^{57} \mathrm{Fe}\right.$ in this study), $E$ is the energy difference between incident $\mathrm{X}$-ray and the nuclear resonance $E_{0}$ (in $\mathrm{meV}$ ) and $E_{R}=E_{0}^{2} / 2 c^{2}$ is the free recoil energy (that is, $1.956 \mathrm{meV}$ for the $E_{0}=14.4125 \mathrm{keV}$ nuclear transition of ${ }^{57} \mathrm{Fe}$ ). Within the harmonic approximation, the $\beta$-factors and the equilibrium isotope fractionation between two phases $\mathrm{A}$ and $\mathrm{B}$ at high temperature ( $>500 \mathrm{~K}$; ref. 32$)$ can be calculated from $\langle F\rangle$ given above using the following relations ${ }^{20,32}$ :

$$
1,\left.000 \ln \beta^{56} \mathrm{Fe}\right|^{54} \mathrm{Fe}=1,000\left(\frac{1}{54}-\frac{1}{56}\right) \frac{\hbar^{2}}{8 k^{2} T^{2}}\langle F\rangle=2,904 \frac{\langle F\rangle}{T^{2}},
$$

and

$$
\Delta^{56} \mathrm{Fe}_{B-A}^{\mathrm{eq}}=\left(\delta^{56} \mathrm{Fe}_{B}-\delta^{56} \mathrm{Fe}_{A}\right)_{\mathrm{eq}}=2,904 \frac{\langle F\rangle_{B}-\langle F\rangle_{A}}{T^{2}},
$$

where $\Delta^{56} \mathrm{Fe}_{B-A}^{\mathrm{eq}}$ is the permil difference in isotopic ratios $\left({ }^{56} \mathrm{Fe} /{ }^{54} \mathrm{Fe}\right)$ of phases $A$ and $B$ at equilibrium (that is, if those phases were juxtaposed and the isotopes of iron partitioned between them according to the laws of equilibrium thermodynamics), $k$ is Boltzmann's constant, $\hbar$ is the reduced Planck constant and $T$ is temperature. The mean force constants $\langle F\rangle$ of iron bonds in the samples were calculated from NRIXS spectra using the SciPhon software, which includes a correction for non-constant baseline. The uncertainties on the force constant measurements $(95 \%$ confidence interval, comprising both systematic and random errors) are $\sim 5-10 \%$. The $\langle F\rangle$ values from SciPhon agree with PHOENIX but those from PHOENIX without baseline subtraction appear more scattered (Supplementary Figs 2 and 3). Several parameters that can be calculated from NRIXS data by using SciPhon, have been compiled in Supplementary Table 2, including estimates of the Lamb-Mössbauer factor, kinetic energy per atom, force constant, internal energy, vibrational specific heat, vibrational entropy, critical temperature, sound velocities (Debye, compressional-wave and shear-wave) and coefficients of the polynomial used to calculate $\beta$-factors at any temperature.

Data availability. The data sets generated during and/or analysed during the current study are available as Supplementary Information and from the corresponding authors.

\section{References}

1. Beard, B. L. \& Johnson, C. M. Fe isotope variations in the modern and ancient earth and other planetary bodies. Rev. Mineral. Geochem. 55, 319-357 (2004).

2. Poitrasson, F., Halliday, A. N., Lee, D.-C., Levasseur, S. \& Teutsch, N. Iron isotope differences between Earth, Moon, Mars and Vesta as possible records of contrasted accretion mechanisms. Earth Planet. Sci. Lett. 223, 253-266 (2004)

3. Williams, H. M. et al. Iron isotope fractionation and the oxygen fugacity of the mantle. Science 304, 1656-1659 (2004).

4. Weyer, S. et al. Iron isotope fractionation during planetary differentiation. Earth Planet. Sci. Lett. 240, 251-264 (2005).

5. Schoenberg, R. \& Blanckenburg, F. V. Modes of planetary-scale Fe isotope fractionation. Earth Planet. Sci. Lett. 252, 342-359 (2006).

6. Teng, F.-Z., Dauphas, N., Huang, S. \& Marty, B. Iron isotopic systematics of oceanic basalts. Geochim. Cosmochim. Acta 107, 12-26 (2013).

7. Polyakov, V. B. Equilibrium iron isotope fractionation at core-mantle boundary conditions. Science 323, 912-914 (2009).

8. Williams, H. M., Wood, B. J., Wade, J., Frost, D. J. \& Tuff, J. Isotopic evidence for internal oxidation of the Earth's mantle during accretion. Earth Planet. Sci. Lett. 321-322, 54-63 (2012).

9. Frost, D. J. \& McCammon, C. A. The redox state of Earth's mantle. Annu. Rev Earth Planet. Sci. 36, 389-420 (2008).

10. Rubie, D. C. et al. Heterogeneous accretion, composition and core-mantle differentiation of the Earth. Earth Planet. Sci. Lett. 301, 31-42 (2011).

11. Wood, B. J., Walter, M. J. \& Wade, J. Accretion of the Earth and segregation of its core. Nature 441, 825-833 (2006).

12. Kump, L. R., Kasting, J. F. \& Barley, M. E. Rise of atmospheric oxygen and the 'upside-down' Archean mantle. Geochem. Geophys. Geosyst. 2, 1025 (2001).

13. Frost, D. J., Mann, U., Asahara, Y. \& Rubie, D. C. The redox state of the mantle during and just after core formation. Phil. Trans. R. Soc. Lond. A Math. Phys. Eng. Sci. 366, 4315-4337 (2008).

14. Wade, J. \& Wood, B. J. Core formation and the oxidation state of the Earth. Earth Planet. Sci. Lett. 236, 78-95 (2005).

15. Wang, K. et al. Iron isotope fractionation in planetary crusts. Geochim. Cosmochim. Acta 89, 31-45 (2012) 
16. Sossi, P. A., Nebel, O., Anand, M. \& Poitrasson, F. On the iron isotope composition of Mars and volatile depletion in the terrestrial planets. Earth Planet. Sci. Lett. 449, 360-371 (2016).

17. Weyer, S. \& Ionov, D. A. Partial melting and melt percolation in the mantle: The message from Fe isotopes. Earth Planet. Sci. Lett. 259, 119-133 (2007).

18. Dauphas, N. et al. Iron isotopes may reveal the redox conditions of mantle melting from Archean to Present. Earth Planet. Sci. Lett. 288, 255-267 (2009).

19. Craddock, P. R., Warren, J. M. \& Dauphas, N. Abyssal peridotites reveal the near-chondritic Fe isotopic composition of the Earth. Earth Planet. Sci. Lett. 365, 63-76 (2013).

20. Dauphas, N. et al. Magma redox and structural controls on iron isotope variations in Earth's mantle and crust. Earth Planet. Sci. Lett. 398, 127-140 (2014).

21. Zhao, X., Zhang, H., Zhu, X., Tang, S. \& Tang, Y. Iron isotope variations in spinel peridotite xenoliths from North China Craton: Implications for mantle metasomatism. Contr. Mineral. Petrol 160, 1-14 (2010).

22. Poitrasson, F., Delpech, G. \& Grégoire, M. On the iron isotope heterogeneity of lithospheric mantle xenoliths: Implications for mantle metasomatism, the origin of basalts and the iron isotope composition of the Earth. Contr. Mineral. Petrol 165, 1243-1258 (2013).

23. Poitrasson, F., Roskosz, M. \& Corgne, A. No iron isotope fractionation between molten alloys and silicate melt to $2000{ }^{\circ} \mathrm{C}$ and $7.7 \mathrm{GPa}$ : Experimental evidence and implications for planetary differentiation and accretion. Earth Planet. Sci. Lett. 278, 376-385 (2009).

24. Hin, R. C., Schmidt, M. W. \& Bourdon, B. Experimental evidence for the absence of iron isotope fractionation between metal and silicate liquids at $1 \mathrm{GPa}$ and $1250-1300{ }^{\circ} \mathrm{C}$ and its cosmochemical consequences. Geochim. Cosmochim. Acta 93, 164-181 (2012).

25. Shahar, A. et al. Pressure-dependent isotopic composition of iron alloys. Science 352, 580-582 (2016).

26. Hernlund, J. W., Thomas, C. \& Tackley, P. J. A doubling of the post-perovskite phase boundary and structure of the Earth's lowermost mantle. Nature 434, 882-886 (2005)

27. Caracas, R. The influence of hydrogen on the seismic properties of solid iron. Geophys. Res. Lett. 42, 3780-3785 (2015).

28. Wood, B. J., Li, J. \& Shahar, A. Carbon in the core: Its influence on the properties of core and mantle. Rev. Mineral. Geochem. 75, 231-250 (2013).

29. Lee, S. K. et al. X-ray Raman scattering study of $\mathrm{MgSiO}_{3}$ glass at high pressure: Implication for triclustered $\mathrm{MgSiO}_{3}$ melt in Earth's mantle. Proc. Natl Acad. Sci. USA 105, 7925-7929 (2008).

30. Murakami, M. et al. High-pressure radiative conductivity of dense silicate glasses with potential implications for dark magmas. Nat. Commun. 5, 5428 (2014)

31. Williams, Q. \& Jeanloz, R. Spectroscopic evidence for pressure-induced coordination changes in silicate glasses and melts. Science 239, 902-905 (1988).

32. Dauphas, N. et al. A general moment NRIXS approach to the determination of equilibrium $\mathrm{Fe}$ isotopic fractionation factors: application to goethite and jarosite. Geochim. Cosmochim. Acta 94, 254-275 (2012).

33. Liu, J. et al. Seismic parameters of hcp-Fe alloyed with Ni and Si in the Earth's inner core. J. Geophys. Res. 121, 610-623 (2016).

34. Lin, J.-F. et al. Sound velocities of iron-nickel and iron-silicon alloys at high pressures. Geophys. Res. Lett. 30, 2112 (2003).

35. Lin, J.-F. et al. Magnetic transition and sound velocities of $\mathrm{Fe}_{3} \mathrm{~S}$ at high pressure: Implications for Earth and planetary cores. Earth Planet. Sci. Lett. 226, 33-40 (2004).

36. Mysen, B. \& Richet, P. Silicate Glasses and Melts: Properties and Structure 544 (Elsevier Science, 2005).

37. Sanloup, C. et al. Structural change in molten basalt at deep mantle conditions. Nature 503, 104-107 (2013).

38. Alfe, D., Kresse, G. \& Gillan, M. J. Structure and dynamics of liquid iron under Earth's core conditions. Phys. Rev. B 61, 132-142 (2000).

39. Laio, A., Bernard, S., Chiarotti, G. L., Scandolo, S. \& Tosatti, E. Physics of iron at Earth's core conditions. Science 287, 1027-1030 (2000).

40. Roskosz, M. et al. Spinel-olivine-pyroxene equilibrium iron isotopic fractionation and applications to natural peridotites. Geochim. Cosmochim. Acta 169, 184-199 (2015).

41. Hu, M. Y., Toellner, T. S., Dauphas, N., Alp, E. E. \& Zhao, J. Moments in nuclear resonant inelastic $\mathrm{X}$-ray scattering and their applications. Phys. Rev. B 87, 064301 (2013).

42. Blanchard, M. et al. Reduced partition function ratios of iron and oxygen in goethite. Geochim. Cosmochim. Acta 151, 19-33 (2015).

43. Polyakov, V. B., Mineev, S. D., Clayton, R. N., Hu, G. \& Mineev, K. S. Determination of tin equilibrium isotope fractionation factors from synchrotron radiation experiments. Geochim. Cosmochim. Acta 69, 5531-5536 (2005).

44. Shahar, A., Young, E. D. \& Manning, C. E. Equilibrium high-temperature Fe isotope fractionation between fayalite and magnetite: an experimental calibration. Earth Planet. Sci. Lett. 268, 330-338 (2008).

45. Li, J. \& Agee, C. B. Geochemistry of mantle-core differentiation at high pressure. Nature 381, 686-689 (1996).
46. Rubie, D. C., Melosh, H. J., Reid, J. E., Liebske, C. \& Righter, K. Mechanisms of metal-silicate equilibration in the terrestrial magma ocean. Earth Planet. Sci. Lett. 205, 239-255 (2003).

47. Siebert, J., Badro, J., Antonangeli, D. \& Ryerson, F. J. Metal-silicate partitioning of Ni and Co in a deep magma ocean. Earth Planet. Sci. Lett. 321-322, 189-197 (2012).

48. Andrault, D. et al. Solidus and liquidus profiles of chondritic mantle: implication for melting of the Earth across its history. Earth Planet. Sci. Lett. 304, 251-259 (2011).

49. Righter, K. \& Drake, M. J. Core formation in Earth's Moon, Mars, and Vesta. Icarus 124, 513-529 (1996).

50. Righter, K. Siderophile element depletion in the angrite parent body (APB) mantle: due to core formation? Lunar Planet. Sci. Confer. 39, 1936 (2008).

51. Wang, K. et al. Iron isotopic compositions of angrites and Stannern-trend eucrites. Lunar Planet. Sci. Confer. 43, 1146 (2012).

52. Dauphas, N., Poitrasson, F., Burkhardt, C., Kobayashi, H. \& Kurosawa, K. Planetary and meteoritic $\mathrm{Mg} / \mathrm{Si}$ and $\delta^{30} \mathrm{Si}$ variations inherited from solar nebula chemistry. Earth Planet. Sci. Lett. 427, 236-248 (2015).

53. Pringle, E. A., Moynier, F., Savage, P. S., Badro, J. \& Barrat, J.-A. Silicon isotopes in angrites and volatile loss in planetesimals. Proc. Natl Acad. Sci. USA 111, 17029-17032 (2014).

54. Mao, H.-K., Xu, J. \& Bell, P. M. Calibration of the ruby pressure gauge to 800 kbar under quasi-hydrostatic conditions. J. Geophys. Res. 91, 4673-4676 (1986)

55. Akahama, Y. \& Kawamura, H. Pressure calibration of diamond anvil Raman gauge to $410 \mathrm{GPa}$. J. Phys. Conf. Ser. 215, 012195 (2010).

56. Rustad, J. R. \& Yin, Q.-Z. Iron isotope fractionation in the Earth's lower mantle. Nat. Geosci. 2, 514-518 (2009).

\section{Acknowledgements}

We thank L. Dubrovinsky for providing the ${ }^{57} \mathrm{Fe}$-enriched $\mathrm{Fe}_{86.8} \mathrm{Ni}_{8.6} \mathrm{Si}_{4.6}$ alloy sample and Y. Fei for providing the ${ }^{57} \mathrm{Fe}$-enriched $\mathrm{Fe}_{3} \mathrm{~S}$ sample. We thank J. Yang for experimental assistance and I. Kuang for assisting with editing the manuscript. J.-F.L. acknowledges support from the US National Science Foundation Geophysics and CSEDI Programs as well as the Center for High Pressure Science and Technology Advanced Research (HPSTAR). HPSTAR is supported by NSAF (Grant Number U1530402). N.D. acknowledges support from NSF (Cooperative Studies of the Earth's Deep Interior, EAR150259; Petrology and Geochemistry, EAR144495) and NASA (Laboratory Analysis of Returned Samples, NNX14AK09G; Cosmochemistry, OJ-30381-0036A and NNX15AJ25G). M.R. acknowledges support from the French ANR (2011JS56 004 01, FrIHIDDA). W.B. acknowledges the support from the Consortium for Materials Properties Research in Earth Sciences (COMPRES), the National Science Foundation (NSF) through Grant Number DMR-1104742. We acknowledge GSECARS and HPCAT of the Advanced Photon Source for use of the diffraction and ruby facilities. This research used resources of the Advanced Photon Source, a US Department of Energy (DOE) Office of Science User Facility operated for the DOE Office of Science by Argonne National Laboratory under Contract No. DE-AC02-06CH11357. We thank three anonymous reviewers for providing very constructive comments and suggestions.

\section{Author contributions}

J.-F.L., J.L., N.D. and M.R. designed the project. M.R. synthesized the glass sample. J.L., H.Y., M.Y.H., W.B., J.Z., E.E.A. and J.-F.L. conducted most high-pressure NRIXS experiments. M.R., N.D. and J.Y.H. conducted some high-pressure NRIXS experiments on basaltic glass up to $5 \mathrm{GPa}$. J.L. and N.D. analysed the data and J.L. modelled the results. J.L. wrote the draft and all authors contributed to the revision of the manuscript.

\section{Additional information}

Supplementary Information accompanies this paper at http://www.nature.com/ naturecommunications

Competing financial interests: The authors declare no competing financial interests

Reprints and permission information is available online at http://npg.nature.com/ reprintsandpermissions/

How to cite this article: Liu, J. et al. Iron isotopic fractionation between silicate mantle and metallic core at high pressure. Nat. Commun. 8, 14377 doi: 10.1038/ncomms14377 (2017).

Publisher's note: Springer Nature remains neutral with regard to jurisdictional claims in published maps and institutional affiliations.

This work is licensed under a Creative Commons Attribution 4.0 International License. The images or other third party material in this article are included in the article's Creative Commons license, unless indicated otherwise in the credit line; if the material is not included under the Creative Commons license, users will need to obtain permission from the license holder to reproduce the material. To view a copy of this license, visit http://creativecommons.org/licenses/by/4.0/

(C) The Author(s) 2017 